\title{
Assessment of the Glomerular Filtration Rate in Living and Cadaver Donor Recipients Within 12 Months of Kidney Transplant
}

Hossein Saffari

Tehran University of Medical Sciences

Hamid Tavakoli ( $\square$ hamid.tavakoli@ubc.ca )

University of British Columbia https://orcid.org/0000-0003-0574-7739

Mohammad Javad Soleimani

Tehran University of Medical Sciences

Research article

Keywords: Kidney Transplantation, GFR, Cadaver Donor, Living Donor, Transplant Rejection

Posted Date: August 24th, 2020

DOI: https://doi.org/10.21203/rs.3.rs-54055/v1

License: (c) (i) This work is licensed under a Creative Commons Attribution 4.0 International License.

Read Full License 


\section{Abstract}

Background: Among patients with urologic disease, end-stage renal disease (ESRD) have the highest mortality rate. The choice of treatment for patients with ESRD is transplantation. The primary objective of this study was to assess the trend of renal function test in cadaver and living donor groups within a year after the surgery.

Method: We included ESRD patients who were admitted to our hospital's clinic from 2001 to 2014. The glomerular filtration rate (GFR) was the outcome of interest.

Results: A total of 381 individuals were included in this study, of whom 246 (64.6\%) were males. the mean age was 40.8 years $(S D=13.2)$. In this study, $291(76.4 \%)$ patients received a transplant from a live donor. In the cadaver group, the GFR decreased by $3.8 \mathrm{~mL} / \mathrm{min}$ ( $95 \%$ confidence interval [CI], 1.2-5.0) per six months, while in the living donor group, it decreased by $1.4 \mathrm{~mL} / \mathrm{min}(95 \% \mathrm{Cl}, 0.3-2.5)$. These trends were not significantly different. The GFR of the living donor group was $0.4 \mathrm{~mL} / \mathrm{min}(95 \% \mathrm{Cl},-1.6-2.3$, $\mathrm{p}=0.72$ ) higher than that of the cadaver donor group per six months, which was not significantly different. The rejection rate was lower in the live donor group (odds ratio $=0.54[95 \% \mathrm{Cl},-0.39-0.74], \mathrm{p}<0.001$ ). The rejection rate decreased over the study period by $71 \%$ every six months, and this decrease did not significantly differ between the study groups.

Conclusions: Although the total GFR in the live donor group was higher, given the higher GFR at the time of surgery in the live donor group, the decrease rate in GFR seemed identical in the study groups.

\section{Background}

The mortality rate in patients with end-stage renal disease (ESRD) is highest among patients with urologic diseases, at close to $20 \%$ of patients even with dialysis[1]. The prevalence of ESRD is increasing, and in the United States, 360 per one million people undergo renal replacement therapy (RRT)[2]. Transplantation is the choice of treatment for this disease, and compared with maintenance therapies, such as dialysis, it significantly decreases the morbidity and mortality rate; however, RRT decreases the burden of disease and improves the quality of life of patients[3]. Given the excellent outcomes of RRT and shortage of live donors, the use of cadaver donors is strongly encouraged[4]. A cost-effectiveness analysis that evaluated the economic effects and patients' quality of life also supports cadaver transplantation[5]. In 2006 in Iran, of 21,251 patients who underwent RRT, 1,066 involved kidneys from deceased donors[6]. There is general agreement that the survival of patients who receive a kidney from a live donor is longer than that of patients who receive an organ from a cadaver donor, and some studies have shown that this difference might be explained by the severity of disease and baseline characteristics of individuals[7].

This study was designed to evaluate the substantial outcomes of kidney transplantation. Renal function within the first year of surgery is one of the best indicators of long-term graft survival[8,9]. Therefore, the primary objective of this study was to compare the trends in renal function within the first year of 
transplantation between living donor and cadaver donor recipients. The second objective of our study was to compare the likelihood of rejection between the two groups in the study.

\section{Methods}

We conducted a historical cohort study for patients with a history of kidney transplantation in ShahidHasheminejad Hospital from 2001 to 2014. We measured the outcome variables at baseline, 1 month, 6 months, and 12 months after transplantation.

We used patient charts throughout the study period and conducted phone calls to collect the missing data. We excluded individuals from the study in cases in which contact via telephone was not possible. A single surgery unit was in charge of all transplantation throughout the study period.

\section{Exposure:}

The exposure of interest in this study was the source of transplant, which was either live or cadaver donors. There were multiple harvest units in Tehran to collect cadaver kidney. To mitigate the likelihood of cold ischemia, we transplanted all the kidneys immediately after we received them, as they were prepared within 3 hours of harvesting.

For live donor recipients, we assessed underlying disease, immunological evaluations, and kidney artery assessment with CT-angiography (computed tomography angiography). In a few cases, we performed angiography for artery assessment.

We excluded donors with multiple arteries and individuals with a body mass index (BMI) greater than 30 . For left nephrectomy, we used the transperitoneal method (open transperitoneal donor nephrectomy) with a midline incision, and for right nephrectomy, we used a right flank incision.

The immunosuppression protocol in both study groups was comprised of mycophenolate mofetil, cyclosporine.

\section{Outcome:}

The glomerular filtration rate (GFR) was the primary outcome. GFR is a powerful indicator for estimating long-term patient survival. To calculate the GFR, we used creatinine clearance based on the CockcroftGault formula[10]. We excluded patients without GFR information in months 6 and 12 of the study.

\section{Confounders:}

We adjusted the analysis for potential confounding variables, which we extracted from the charts or obtained via telephone interviews.

We used age, BMl at the time of transplantation, and gender as potential demographic confounder variables. A history of diabetes mellitus was also included as a factor that might strongly affect survival 
after transplantation. Lastly, we included variables that addressed the severity of kidney disease, including a history of nephrectomy, re-operation, previous transplantation, and a history of delayed graft function (DGF). The baseline (preoperative) GFR was also used as a covariate to adjust the model.

\section{Statistical analysis:}

SAS Enterprise Guide (Version 6.1, Cary, NC, USA) was used for all analyses. Generalised linear model (GLM) with generalised estimating equations were used to account for the clustered nature of the data (four observation units for the same patient). All aforementioned exposures of interest and confounders were defined as independent variables in the model. GFR was defined as a dependent variable, and a normal distribution was assumed.

We used the multiple imputation (MI) method to handle missing variables. The units of time in this study were ordinal variables, which represented the time of measurement at month 1, 6, and 12 after the date of transplantation.

For the secondary objective, we calculated the rate of rejection using a GLM model with a binomial distribution and logit function. This model generated the odds ratio (OR) of rejection in the cadaver donor group compared to that in the living donor group (cadaver assigned as the reference group). To evaluate the effect of time on the rejection rate among the groups, we performed an interaction of time and donor type, and the coefficient for this interaction indicated whether the likelihood of rejection increased or decreased over the study period.

\section{Results}

A total of 442 individuals were registered in the study, and after excluding patients without baseline GFR data and with other exclusion criteria, 381 individuals were included in this study (the rest were excluded because of Lack of follow up). Among the individuals included in the study, 246 (64.6\%) were male, and the mean age was 40.8 years $(S D=13.2)$. None of the patients included received a transplant from their relatives. In this study, 291 (76.4\%) patients received a transplant from a living donor. Table 1 shows the patients' characteristics and covariate distributions.

The data showed that the GFR of the living donor group was $0.35 \mathrm{~mL} / \mathrm{min}$ higher than that of the cadaver group at every time point, but this difference was not statistically significant ( $95 \%$ confidence interval [CI], -1.56 to $2.26, p=0.72$ ). Table 2 shows the association of other covariates with GFR changes.

The coefficients for the potential confounders showed female gender, older age, history of DGF, and lower baseline GFR were significantly associated with decreased GFR over the study time.

The separate trend analyses of study groups indicated that the GFR level decreased in both live and cadaver donor recipients $(3.10 \mathrm{~mL} / \mathrm{min}$ per 6 months [ $95 \% \mathrm{Cl}, 1.21-5.0]$ and $1.38 \mathrm{~mL} / \mathrm{min}$ per 6 months [95\% Cl, 0.26-2.50], respectively). 
The second set of analyses indicated that rejection was less likely in the live donor group (OR=0.54 [95\% $\mathrm{Cl}, 0.39-0.74], \mathrm{p}<0.001)$. The rejection rate significantly decreased throughout the study period in both group by $71 \%[\mathrm{OR}=0.29[95 \% \mathrm{Cl}, 0.21-0.40], \mathrm{p}<0.001)$ every 6 months after transplant.

The interaction of measurement time and donor type did not significantly differ between the groups (OR= 0.99 [95\% Cl, 0.68-1.45], $\mathrm{p}=0.9769$ ). This interaction indicated that although the cadaver group had a higher likelihood of rejection, this risk remained constant compared to that of the living donor group throughout the study period.

\section{Discussion}

Kidney transplantation is the preferred choice of treatment for ESRD. GFR measurement in the year after transplantation is a strong indicator of the long-term survival of the kidney. Given the scarcity of living donors the waiting time are increasing for ESRD and patients and it plays such an important roll in disease progress. To compensate this issue RRT from cadaver donor is one of effective approach. In some studies researchers even evaluate the efficacy and cost effectiveness of hepatitis C-positive donor RRT for hepatitis C-negative recipients[11, 12].

Our objective in this study was to compare the trend of this marker in cadaver versus live donor recipients. In Iran, the cost and availability of organs from live donors are significantly lower than those of organs from cadaver donors. Thus, people are receiving kidneys from cadavers, which usually has a longer waiting time. Our main objective was to observe how the GFR changes over time after transplantation in patients who received kidneys from living versus cadaver donors. The results showed that the difference between the GFR of the patients in the two study groups was mostly explained by the baseline difference in these groups. Although the GFR at all time points was significantly lower in the cadaver group, the trend of declining GFR in both groups was similar.

In the current study, the GFR at baseline was significantly lower in patients who received a cadaver transplant. This result can be explained by the longer waiting time that this group experiences compared with patients who received a kidney from live donors. The data showed that cadaver donor recipients had a better response within one month after the procedure. This finding can be explained by the severity of disease and decreasing GFR in this group. Nevertheless, after the first month, the GFR slightly decreased, and the trend became similar to that of the live donor recipients. Although the trend in both groups was negative and cadaver patients had significantly lower GFRs, there was a significant difference in the slope of the decrease in the GFR in these two groups. This finding indicated that given the differences in baseline GFR, the downward trend was almost identical. Lee $S$ et al[13] observed cases of live and cadaver kidney transplantation from 1995 to 2008. They measured creatinine levels 5 and 10 years after the operation and did not find a significant difference between the two groups. Wigger $M$ et al[14] studied patients for 16 years and measured the GFR in 5-year intervals. They reported that the GFR decreased from $88 \mathrm{~mL} / \mathrm{min}$ to $68 \mathrm{~mL} / \mathrm{min}$. 
The results of our study showed that the likelihood of rejection was higher in cadaver donor recipients, especially in the first months after the operation, although it decreased in both groups. Our findings aligned with the findings of other studies, which indicated that the likelihood of rejection is higher in the first months after transplantation, especially five to seven days after transplantation[15]. Although we showed a better survival rate for live donor recipients, Campbell et al[16] reported that live donor recipients had a much higher rate of rejection and more severe rejection.

The major strength of this study was its relatively large sample size, its consistent method of surgery, and its long study period, which helped us identify the effects of exposure on the survival of a kidney transplant. We were unable to identify the socio-economic status of the patients and the exact time patients underwent dialysis, both of which may potentially affect kidney survival after transplantation. This factor and underlying comorbidities might potentially change kidney survival after transplantation.

\section{Conclusion}

Given the scarcity of living donors, cadaver donors are a reasonable substitute. Although some experts have raised some concern about patient survival, we showed that the decline in kidney function in the cadaver group was equal to that in the living donor group. However, the rejection rate in the early stages of transplantation was higher in cadaver recipients. Future research in which the survival of these two types of transplant is considered should have a longer follow-up period and measure more potential confounders. In addition, more cost-effectiveness analyses can show the long-term performance of these two types of procedures from a population-based perspective.

\section{Abbreviations}

ESRD: End-Stage Renal Disease

RTT: Renal Replacement Therapy

CT-angiography: Computed Tomography Angiography

BMI: Body Mass Index

GFR: Glomerular Filtration Rate

DGF: Delayed Graft Function

GLM: Generalised Linear Model

MI: Multiple Imputation

OR: Odds Ratio 


\section{Declarations}

\section{Availability of data and materials}

The datasets used and/or analysed during the current study available from the corresponding author on reasonable request.

\section{Author contribution}

HS and MS articulated and initiated the idea. HS and MS designed the study. HT implemented all the statistical analyses. HT wrote the first draft of the manuscript. All authors critically commented on the manuscript and approved the final version.

\section{Funding}

There is no funding or any financial aid was provided for this study.

\section{Competing interests}

All authors declare that they have no conflict of interest.

\section{Consent for publication}

Not applicable.

\section{Ethics approval and consent to participate}

The current study was approved by the Iran University of Medical Sciences' Clinical Research Ethics Board (1398.1235). Patients at the admission to the hospital had signed consent forms approved by Iran university of medical sciences to use their medical documents for the research purposes.

\section{Acknowledgements}

Not applicable.

\section{References}

1. Go AS, Chertow GM, Fan D, McCulloch CE, Hsu C. Chronic kidney disease and the risks of death, cardiovascular events, and hospitalization. N Engl J Med. 2004;351:1296-305.

2. Schnuelle P, Lorenz D, Trede M, Van Der Woude FJ. Impact of renal cadaveric transplantation on survival in end-stage renal failure: evidence for reduced mortality risk compared with hemodialysis during long-term follow-up. J Am Soc Nephrol JASN. 1998;9:2135-41.

3. Abecassis M, Bartlett ST, Collins AJ, Davis CL, Delmonico FL, Friedewald JJ, et al. Kidney transplantation as primary therapy for end-stage renal disease: a National Kidney 
Foundation/Kidney Disease Outcomes Quality Initiative (NKF/KDOQITM) conference. Clin J Am Soc Nephrol CJASN. 2008;3:471-80.

4. Nemati E, Einollahi B, Lesan Pezeshki M, Porfarziani V, Fattahi MR. Does kidney transplantation with deceased or living donor affect graft survival? Nephro-Urol Mon. 2014;6:e12182.

5. YaghoubiFard S, Goudarzi R, Etminan A, Baneshi M, Barouni M, Jafari Sirizi M. Cost-effectiveness analysis of dialysis and kidney transplant in patients with renal impairment using disability adjusted life years in Iran. Med J Islam Repub Iran. 2016;30:390.

6. Ghods AJ, Mahdavi M. Organ transplantation in Iran. Saudi J Kidney Dis Transplant Off Publ Saudi Cent Organ Transplant Saudi Arab. 2007;18:648-55.

7. Guirado L, Vela E, Clèries M, Díaz JM, Facundo C, García-Maset R, et al. [Why renal transplant from living donors gives better results than cadaver renal transplant?]. Nefrol Publ Of Soc Esp Nefrol. 2008;28:159-67.

8. Hariharan S, McBride MA, Cherikh WS, Tolleris CB, Bresnahan BA, Johnson CP. Post-transplant renal function in the first year predicts long-term kidney transplant survival. Kidney Int. 2002;62:311-8.

9. Salvadori M, Rosati A, Bock A, Chapman J, Dussol B, Fritsche L, et al. Estimated one-year glomerular filtration rate is the best predictor of long-term graft function following renal transplant. Transplantation. 2006;81:202-6.

10. Cockcroft DW, Gault MH. Prediction of creatinine clearance from serum creatinine. Nephron. 1976;16:31-41.

11. Goldfarb DA. Re: Cost-Effectiveness of Hepatitis C-Positive Donor Kidney Transplantation for Hepatitis C-Negative Recipients with Concomitant Direct-Acting Antiviral Therapy. J Urol. 2019;201:431.

12. Kamalkiran M, Ravikiran V, Shashidhar C, Prasad KVR, Yeldandi V. Kidney Transplantation from a Hepatitis C Virus-positive Donor to a Hepatitis C Virus-negative Recipient. Indian J Nephrol. 2018;28:488-9.

13. Lee S, Kim J, Shin M, Kim E, Moon J, Jung G, et al. Comparison of outcomes of living and deceased donor kidney grafts surviving longer than 5 years in Korea. Transplant Proc. 2010;42:775-7.

14. Wigger M, Drückler E, Muscheites J, Stolpe HJ. Course of glomerular filtration rate after renal transplantation and the influence of hypertension. Clin Nephrol. 2001;56:S30-34.

15. Knechtle S, Morris P. Kidney Transplantation - Principles and Practice. 7th edition. 209-211: Elsevier; 2013.

16. Campbell SB, Hothersall E, Preston J, Brown AM, Hawley CM, Wall D, et al. Frequency and severity of acute rejection in live- versus cadaveric-donor renal transplants. Transplantation. 2003;76:1452-7.

\section{Tables}

Table 1: Characteristics of individuals in study groups 


\begin{tabular}{|lll|}
\hline Variable & Alive donor & Cadaver donor \\
\hline Total & $217(64.58 \%)$ & $65(61.32 \%)$ \\
\hline Sex & $101(34.71 \%)$ & $34(37.78 \%)$ \\
\hline Nephrectomy & $1(0.34 \%)$ & $3(3.33 \%)$ \\
\hline Re Operation & $11(3.78 \%)$ & $5(5.56 \%)$ \\
\hline Rejection & $77(26.46 \%)$ & $39(43.33 \%)$ \\
\hline DM & $51(17.53 \%)$ & $18(20 \%)$ \\
\hline DGF & $22(7.56 \%)$ & $14(15.56 \%)$ \\
\hline Age (SD)* & $40.66(13.29)$ & $41.42(12.75)$ \\
\hline BMI (SD) & $24.31(2.05)$ & $24.6(1.89)$ \\
\hline Baseline GFR (SD) & $66.86(19.55)$ & $60.43(23.83)$ \\
\hline
\end{tabular}

*SD: Standard Deviation

Table 2: Association of Donor type with changes in GFR after adjustment for potential confounders

\begin{tabular}{|llll|}
\hline Variable & GFR change $(\mathrm{mL} / \mathrm{min})$ & $95 \%$ Cl lower-upper & p-value \\
\hline Time (every 6 months) & -1.78 & $-2.75--0.81$ & $<.0001$ \\
\hline Age & -0.08 & $-0.15--0.01$ & 0.0186 \\
\hline Sex (reference=female) & 3.66 & $1.92-5.39$ & $<.0001$ \\
\hline Donor (reference=cadaver) & 0.35 & $-1.56-2.26$ & 0.7212 \\
\hline GFR at baseline & 0.69 & $0.64-0.73$ & $<.0001$ \\
\hline BMI & 0.20 & $-0.24-0.63$ & 0.3779 \\
\hline Nephrectomy & -4.99 & $-14.27-4.29$ & 0.2919 \\
\hline Re Operation & -6.17 & $-11.25--1.09$ & 0.0174 \\
\hline DM & -1.73 & $-4.12-0.66$ & 0.1555 \\
\hline DGF & -4.59 & $-7.92--1.27$ & 0.0069 \\
\hline
\end{tabular}

Table 3: Association of Donor type with likelihood of rejection after adjustment for potential confounders 


\begin{tabular}{|llll|}
\hline Variable & GFR change (odds ratio) & $95 \%$ Cl lower-upper & P value \\
\hline Time (every 6 months) & 0.29 & $0.25-0.34$ & $<.0001$ \\
\hline Age & 0.99 & $0.98-1.00$ & 0.0443 \\
\hline Sex (reference=female) & 1.24 & $0.92-1.68$ & 0.1585 \\
\hline Donor (reference=cadaver) & 0.54 & $0.39-0.74$ & 0.0001 \\
\hline GFR at baseline & 0.98 & $0.97-0.99$ & $<.0001$ \\
\hline BMI & 1.23 & $1.14-1.33$ & $<.0001$ \\
\hline Nephrectomy & 1.19 & $0.23-6.15$ & 0.8368 \\
\hline Re Operation & 1.77 & $0.84-3.74$ & 0.1344 \\
\hline DM & 1.59 & $1.11-2.28$ & 0.0121 \\
\hline DGF & 2.44 & $1.50-3.97$ & 0.0003 \\
\hline
\end{tabular}

\section{Figures}

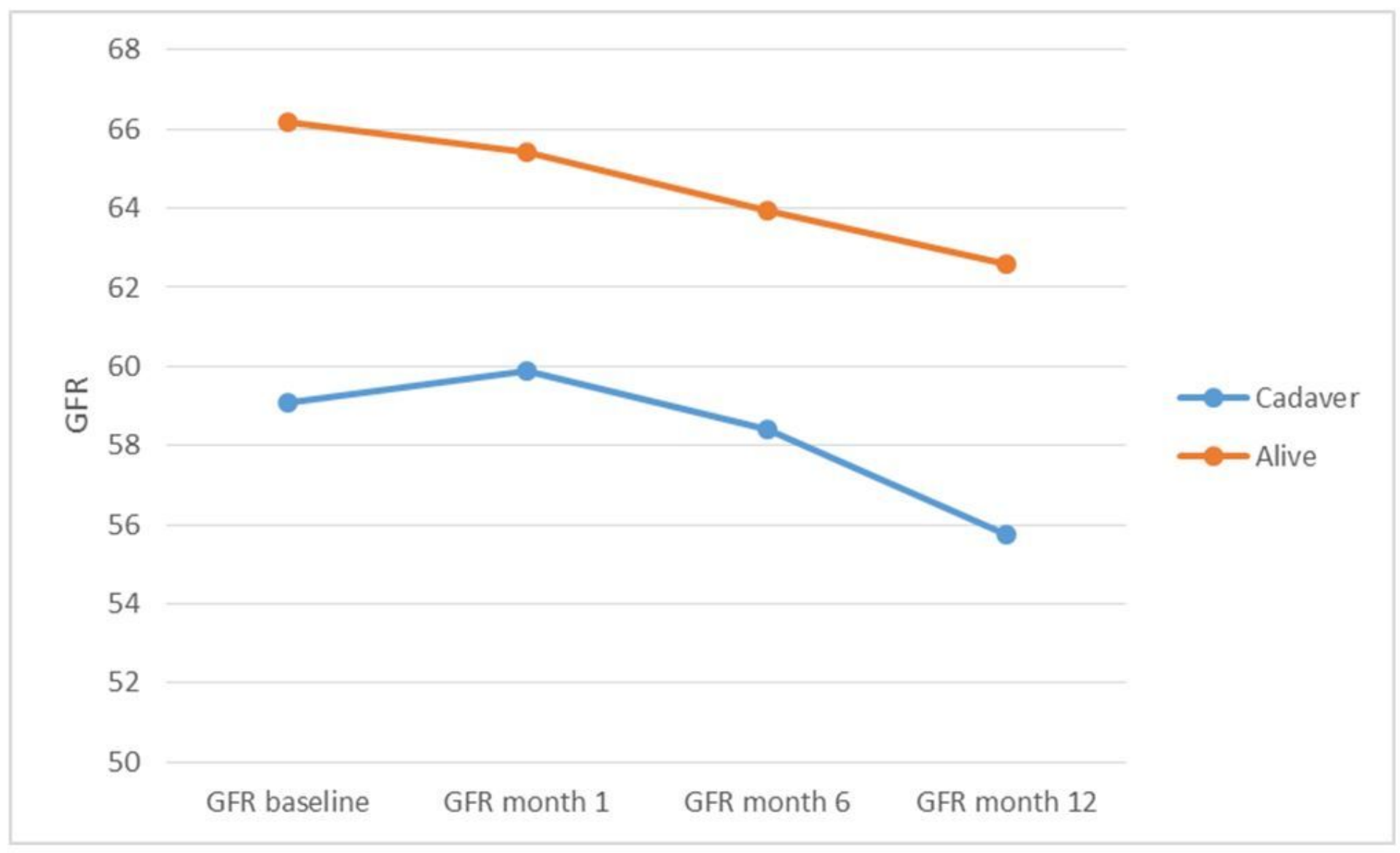

Figure 1 
Average GFR in four times of assessment by donor type 1-GFR in cadaver donor's group 2-GFR in living donor's group 